\section{We need negative metrics too}

Research metrics are

ambiguous - a paper may be cited for positive or negative reasons. Funding agencies and universities focus on positive impact in evaluating research, which increasingly includes alternative metrics ('altmetrics'; see Nature 493, 159 and Nature 495, 437-440; 2013). We think that researchers can generate a more complete account of their impact by including seemingly negative indicators - such as confrontations with important people or legal action — as well as those that seem positive.

To explore this idea, we at the Center for the Study of Interdisciplinarity discussed ways to evaluate the impact of our research activities. We began with common quantitative indicators of scholarly impact (number and place of publications, citation indexing measures, number and size of grant awards, and so on). Warming to our theme, we came up with several other possible indicators, including negative ones (see table for examples and go.nature.com/miytf3 for a complete list).

In this age of increasing demand for accountability, we believe that academics ought to own the impact of their research, rather than have it determined by someone else.

J. Britt Holbrook, Kelli R. Barr,
Keith Wayne Brown University of North Texas, Denton, Texas, USA. britt.holbrook@unt.edu

\section{Campaign tactics and grants don't mix}

Using political-campaign tactics to secure grant awards threatens to oversimplify the science, overwhelm the independent peer-review process, and disregard intellectual-property and confidentiality issues.

Take the European

Commission's Future and Emerging Technologies 'flagship' programme, which in January selected two projects to receive about $€ 1$ billion (US $\$ 1.3$ billion) each over 10 years (see Nature 493, 585-586; 2013). Six projects were shortlisted after a yearlong competition on the basis of scientific review - but also on the success of presentations to the European Parliament and political representatives, promotional videos and television interviews.

Substantial media exposure of the US Brain Research through Advancing Innovative Neurotechnologies (BRAIN) Initiative is inducing speculation on research outcomes well ahead of hard experimental evidence.

Securing broad political consensus for large-scale projects is understandable. Yet applicants for some low-budget grants are now also using social media, promoting proposals by requesting support letters through mass e-mailings and Twitter communications.

However tempting, this could outweigh reasoned peer review. Victor Maojo, Juan Pazos Polytechnic University of Madrid, Spain. vmaojo@fi.upm.es

Casimir A. Kulikowski Rutgers, The State University of New Jersey, Piscataway, New Jersey, USA.

\section{Australian academy is fair to women}

It is not true that the Australian Academy of Science, of which I am president, treats women with disdain (Nature 497, 7; 2013). The absence of women elected as fellows in 2013 is of great concern, but it is an anomaly.

Election of women to our academy has steadily increased, from just one in the 1970s to 27 since 2000. Three of our executive councillors are female, and women chair five out of 22 national committees. This year, half of our early-career awardees and one of four fullcareer awardees are women (see go.nature.com/avrqiy).

That said, our academy still has too few women. Part of the problem is historical and universal (see, for example, Nature 495, 21; 2013). Past policies either discriminated against women or failed to nurture their careers. The academy has urged Australian

\section{OTHER POSSIBLE INDICATORS OF IMPACT}

\begin{tabular}{l|l|} 
Public engagement & Academic community \\
\hline Protests, demonstrations or arrests & Invitations to present, consult or review \\
\hline Provoking lawsuits & Interdisciplinary achievements \\
Angry letters from important people & Adviser appointments \\
Meetings with important people & Reputation of close collaborators \\
\hline Participation in public education & Reputation as a team member \\
\hline Mention by policy-makers & Textbooks authored \\
\hline Public research discussions & Citation in testimonials and surveys \\
Muckraking & Audience size at talks and meetings \\
Quotes in policy documents & Developing a useful metric \\
Rabble rousing & Curriculum input \\
\hline Engagement with citizens abroad & Faculty recommendations, prizes \\
\hline
\end{tabular}

Media
Article downloads
Website hits
Media mentions
Quotes in media
Coining of a phrase
Trending in social media
Blog mentions
Book sales
Buzzword invention
Social-network contacts
Television and radio interviews

science agencies to prioritize career flexibility and has endorsed guidelines for gender equity (see go.nature.com/zi253a).

We are striving to increase the proportion of female fellows by ensuring that high-achieving women are not overlooked for nomination and that our criteria do not disadvantage them. Further measures to improve the gender balance will be considered at the academy's annual general meeting this month.

Suzanne Cory Australian Academy of Science, Canberra. cory@wehi.edu.au

\section{Economic modelling could aid brain map}

Debate over US President Barack Obama's brain-mapping proposal (Nature 495, 19; 2013) would benefit from economic modelling. This would refine thinking on goals, funding and timing amid budget cuts and discussions of governmentsponsored big science.

An example of this approach comes from modelling the time and money required for genomic research to cut adverse drugrelated patient outcomes, using actual data (R. Arnaout et al. Clin. Chem. 59, 649-657; 2013). This reveals how understanding drug-response genomics could lead to cheaper, faster progress, delivering specific, fact-based, actionable insights.

The brain-mapping proposal is broader, perhaps calling for technologies not yet invented, but the intention is still to improve health. Economic modelling could aid comparisons between the proposal and competing investments, engage stakeholders and foster accountability. It would serve the ultimate funding source and beneficiary: the taxpayer. Ramy Arnaout ${ }^{*}$ Beth Israel Deaconess Medical Center, Harvard Medical School, Boston, Massachusetts, USA. rarnaout@bidmc.harvard.edu ${ }^{*}$ On behalf of 4 co-authors. See go.nature.com/brfb2u for full list. 